\title{
OS REPERTÓRIOS DA DISCIPLINA HISTÓRIA DA EDUCAÇÃO: NOBRES OBJETIVOS,EXTENSOS CONTEÚDOS E A BIBLIOGRAFIA DOS MANUAIS
}

\author{
Bruno Gonçalves Borges ${ }^{1}$ \\ Décio Gatti Júnior ${ }^{2}$
}

\section{RESUMO}

O presente artigo apresenta resultados de pesquisa que teve como objetivo investigar a história disciplinar da História da Educação no espaço da formação de professores e profissionais da educação na Universidade Federal de Uberlândia. A necessidade em compreender as finalidades ideais e reais assumidas pelo ensino de História da Educação ao longo do tempo na instituição configurouo problema motivador dessa investigação. $\mathrm{O}$ texto a seguir, traz considerações acerca dos repertórios da disciplina do ponto de vista ideal ou programático. Assim, aborda as condições encontradas e as características fundamentais dos objetivos do ensino, dos conteúdos a serem ensinados e da listagem bibliográfica indicada aos estudantes presentes nos planos de curso levantados que correspondem ao período compreendido entre 1961 e o ano 2000.

Palavras-chave: História da Educação; disciplina; planos de curso; Pedagogia; Universidade Federal de Uberlândia

\section{THE REPERTOIRES OF HISTORY OF EDUCATION: NOBLE PURPOSE, EXTENSIVE SCHOOL SUBJECT AND BIBLIOGRAPHY OF MANUALS}

\begin{abstract}
This paper presents results of research what investigated the disciplinary history of the History of Education in the space of teacher training and professional education at Universidade Federal de Uberlândia. The need to understand the ideals and purposes assumed by the real teaching of history of education over time in the institution set up the problem motivating this research. Hereafter, present considerations of the repertoires of discipline from the standpoint of ideal or programmatic. So deal with the conditions encountered and the fundamental characteristics of the learning objectives, content to be taught and bibliographic listing indicated for students, present in the course plans that correspond to the period between 1961 and 2000.

Keywords: History of Education; discipline; course plans; Pedagogy; "Universidade Federal de Uberlândia"
\end{abstract}

\section{Introdução}

Analisar a composição dos repertórios da disciplina História da Educação na Universidade Federal de Uberlândia (UFU) ao longo de quarenta anos no âmbito da idealização do ensino exigiu a constituição de um corpus documental baseado na recolha de materiais históricos da disciplina como planos de curso, projetos pedagógicos e regulamentações que resultaram na constituição das fontes necessárias à investigação. 
Torna-se necessário precaver o leitor da mudança constante no texto do lugar em que a disciplina investigada esteve em funcionamento. Essas mudanças são fruto das transformações na educação superior da cidade que confluem para a constituição da Universidade Federal de Uberlândia. Assim, nas duas primeiras décadas, a disciplina esteve alocada na Faculdade de Filosofia Ciências e Letras - FFCLU, popularmente conhecida pela sigla FAFI, instituição privada, que se manteve escola isolada de 1960 a 1969, associando-se, ao final deste período, à Universidade de Uberlândia, autarquia estadual e, posteriormente federalizada em 1978.

\section{Sentimento nobre, função devota}

Perceber qualquer prestígio curricular à História da Educaçãoensinada nos cursos de formação de professores parece tarefa difícil, principalmente, considerando a sua trajetória histórica em âmbito mais amplo. No Brasil, por exemplo, parece não serexagero reconhecer a existência de um estatuto de disciplina menor, subsidiária, e mesmo, submetida aos conteúdos considerados mais ilustres dos currículos da Escola Normal e do curso de Pedagogia. Também nas licenciaturas, cursos que formam professores para as mais variadas áreas do saber escolarizado, a formação pedagógica, ainda que presente, não inclui, na maioria das vezes, a disciplina. Quanto a tudo isso, pode-se dizer que sendo a História da Educação

[...] filha tardia da ideia de abordagens múltiplas em Educação; não é incluída, entre as ciências auxiliares com o mesmo escopo das matriciais, quais sejam, Psicologia, Sociologia e Biologia. Assim como a Filosofia não poderia ser denominada apropriadamente de ciência, a História também não o poderia. Assim, a Filosofia e a História da Educação foram incorporadas não exatamente como ciências, mas como disciplinas formadoras (WARDE, 1998, p. 91).

Consequentemente, não se pode ignorar, por exemplo,

[...] que a manutenção, por décadas, da História da Educação como apêndice da Filosofia da Educação, tenha marcado profundamente os seus contornos teóricos e de método. Em verdade, a História da Educação não se apresenta nos currículos dos nossos cursos de formação do magistério [...] como disciplina autônoma, mas como irmã siamesa da Filosofia da Educação (WARDE, 1998, p. 91).

Segundo Warde (1998), "este quadro se manteve, com algumas exceções institucionais, até os anos 1960" e, em muitas ocasiões não chegava a configurar uma disciplina à parte, sendo comum encontrá-la inscrita como Filosofia e História da Educação e vice-versa. Essa percepção leva ao questionamento se haveria resquícios desse modelo na constituição da disciplina História da Educação na UFU.

No período entre 1960 e 1970, no currículo do curso de Pedagogia da instituição investigada, a História da Educação já se apresentava como disciplina autônoma, no que diz respeito ao oferecimento. No entanto, é visível a forte presença da Filosofia, que de forma explícita, está presente nas 480 horas de disciplinas especificamente filosóficas, somadas às 300 horas de fim essencialmente religioso e, presente também de forma oculta, que pela própria característica confessional do curso, imbuía uma perspectiva filosófica de fim salvacionista nas diferentes disciplinas.

Nesse contexto, a História da Educação esteve muito mais atrelada à formação moral e memorialista do que propriamente, ao estudo histórico dos processos educacionais, 
o que encontrava correspondência com o modelo nacionalmente difundido para a área, de reprodução do padrão cristão, que em linhas gerais, pode ser compreendido pela adoção de "uma narrativa contínua, que parte dos modelos de formação supostamente adotados pelas sociedades antigas e medievais para completar-se com os pensadores da educação das idades Moderna e Contemporânea" (BONTEMPI JR, 2007, p. 88). Essa parece ser ao que tudo indica a concepção expressa nos planos de curso da disciplina nos primeiros anos:

\begin{abstract}
História da Educação: Objeto - método - divisão - importância da História da Educação. A época do Tradicionalismo. Os povos primitivos: China Índia, o povo hebreu. A Grécia e a pedagogia da personalidade: Esparta e Atenas. Pitágoras. Aristóteles. A educação encíclica. Roma e a educação da "humanitas": os tempos primitivos - a educação encíclica de Roma - os teóricos da educação - Quintiliano e o ideal do orador. A Idade Média. O cristianismo e a educação. A patrística. A educação para a virtude. Carlos Magno. O império do oriente e os árabes. A educação para o êxtase. A escolástica. A educação secular. As universidades medievais. Reforma e contra-reforma. O humanismo pedagógico na Itália, na Alemanha, na Inglaterra, na França. A educação na América. (EMENTA, FFCLU 1961)
\end{abstract}

A partir de Nunes (1996) identifica-se que mesmo quando "o saber religioso parece não mais marcar esta história, a motivação religiosa ainda está na base da trama social que forja o historiador da educação" (p. 72) e repercute na programação do ensino da disciplina.

Ao observar tanto o que relata a ementa descrita anteriormente, quanto o programa de "pontos trabalhados", que sumariza os temas abordados na disciplina, nota-se o favorecimento dos feitos católicos na educação, sem desprezar, no entanto, teóricos protestantes como Pestalozzi. Outro fator presente é a inexistência de assuntos dedicados à educação brasileira, que, como de costume na época, não encontra espaço diante do empenho com que é dedicado às discussões dos modelos pedagógicos clássicos.

\footnotetext{
HISTÓRIA DA EDUCAÇÃO $-2^{\circ}$ ano. A educação dos tempos primitivos; A educação encíclica; A educação terciária; Quintiliano e o ideal do orador; Fatores políticos e culturais mais importantes na Idade Média; Fatores políticos e culturais mais importantes na Idade Média (repetido); Importância do cristianismo na educação; Os começos da educação cristã; A educação para a virtude; A escolástica como tipo de formação intelectual; As universidades Medievais. HISTÓRIA DA EDUCAÇÃ̃ $-3^{\circ}$ ano. Da $1^{\mathrm{a}}$ a $2^{\mathrm{a}}$ Guerra Mundial; A renovação do naturalismo; A pedagogia da ação; Os grandes teóricos da pedagogia ativista; Métodos que diferenciam o ensino; Métodos que individualizam o ensino; Métodos de trabalho em equipe; Métodos predominantemente socializadores; Pedagogia social e socialista; A pedagogia cultural dos valores; Sistemas de educação pública no século XX; A pedagogia do futuro. (RELAÇÃO DE PONTOS, FFCLU, 1961)
}

Diante do que expõem esses materiais históricos, das pesquisas anteriores sobre o ensino de História da Educação (NUNES, 1996 e WARDE; CARVALHO, 2000) e do ideal estabelecido de formação de "um país grande, uno e cristão" (NUNES, 1996, p. 72), ressonante ainda nos anos 1970, percebe-se, na instituição pesquisada, uma dificuldade de ruptura dos moldes cristãos, impregnados na disciplina duplamente, primeiro, por ser este o entendimento acerca do que seria História da Educação na época e, segundo, 
considerando o lugar originário da disciplina investigada, uma faculdade confessional católica.

Nessa direção, observa-se que com a transição institucional provocada pela criação da Universidade de Uberlândia - UnU, autarquia estadual em 1969 e, mesmo após a sua federalização em 1978, a inspiração cristã não foi apagada da formação acadêmica dos alunos da antiga FFCLU e nos seus desdobramentos posteriores (Centros, Institutos e Faculdades). Os ranços permaneceram, por um longo tempo, na orientação geral dos cursos e, posteriormente, de forma oculta, na prática dos (as) professores (as) ou pelo menos daqueles (as) vinculados (as) à Igreja. Assim,

[...] qual seria o objetivo maior, senão aquele que nos leva a trabalhar pelos valores absolutos, anunciados por Cristo no Evangelho? E de todos os valores que Ele nos ensinou qual é o maior mandamento, senão o amor-caridade, cujo único sentido é o respeito pelo próximo? Esse foi o grande objetivo que a Faculdade Filosofia procurou desenvolver tendo por base a união, a harmonia e o bom relacionamento entre professores, alunos e direção. (REVISTA COMEMORATIVA DO JUBILEU DE PRATA DA FFCLU, 1985, p. 1)

$\mathrm{Na}$ argumentação acima, uma ex-dirigente e professora da instituição, vincula mais uma vez, a existência da faculdade e dos cursos na área de humanas à missão evangelizadora, própria de qualquer ordem religiosa, que no caso, exerceu-a por meio do ensino.

Temos, pois, esperança de que na memória da Universidade Federal de Uberlândia permaneça, norteando as bases filosóficas de sua grande missão, o lema que sempre regeu a história da Faculdade de Filosofia, Ciências e Letras: "Veritas liberabit vos" A verdade vos libertará (REVISTA COMEMORATIVA DO JUBILEU DE PRATA DA FFCLU, 1985, p. 1).

Ao referir-se à memória da UFU, remete-se, na verdade, ao futuro da universidade, que deve resguardar os seus princípios originários, não por acaso, os advindos da faculdade de filosofia, conduzindo a universidade à postura de dívida eterna com a confissão católica, reafirmada, mais uma vez, com o lema da FFCLU, retirado da literatura bíblica de João "8:32", o qual esperava-se manter na instituição federal.

Em tempo, ressalta-se que a devoção evocada no subtítulo não pode ser entendida como indicadora de algo menor, pelo contrário, na época e pelos condicionantes institucionais, o fato da disciplina servir aos outros componentes curriculares foi, justamente, o que caracterizou a História da Educação como nobre pelo papel que desempenhou na formação de professores indistintamente da posição.

\section{Os objetivos (a missão) da História da Educação}

No contexto em que se insere a História da Educação investigada, os objetivos propostos para o ensino da disciplina não poderiam ser diferentes do ideal comum difundido. Nos primeiros quinze anos, foi marcado por uma História da Educação caracterizada como "salvacionista" que a partir de Warde (1998), pode ser entendida como um ensinamento baseado no pragmatismo moral e doutrinário.

Equiparados aos objetivos evangelizadores, os nobres objetivos da História da Educação correspondiam a mais uma ação religiosa, pois atendiam aos mesmos fins. Dessa forma, na História da Educação, o mais importante era destacar os grandes feitos que 
justificassem a ação católica na educação e na sociedade criando, para isso, no aluno, um repositório de histórias harmonicamente organizadas, com ênfase no período medieval e da contra-reforma.

De uma percepção cristã evangelizadora, os objetivos do ensino de História da Educação passam, no final dos anos 1970, a assumir um compromisso de ampliar o tratamento dado à disciplina, principalmente, por meio da diversificação dos conteúdos.

\begin{abstract}
HISTÓRIA DA EDUCAÇÃO I - Educação humanista; educação realista; educação naturalista, educação idealista; evolução do ensino no Brasil; integração e desintegração de fatores (relacionado com o tópico anterior); a educação brasileira após 1964; a ajuda internacional para a educação brasileira no atual estágio da expressão capitalista, sua funcionalidade; a universidade brasileira. HISTÓRIA DA EDUCAÇÃO II - Início dos tempos modernos - a revolução comercial; influências da Reforma; o realismo pedagógico, a nova didática; o iluminismo; o naturalismo pedagógico; a pedagogia da revolução e a educação política; a universidade napoleônica, as Escolas Normais; o neohumanismo; a pedagogia de interesse; pedagogia social; pedagogia experimental; a revolução industrial; educação técnico-vocacional; educação pública; educação feminina; a pedagogia do positivismo e do evolucionismo; a evolução da educação na América; evolução da educação no Brasil; da $1^{\mathrm{a}}$ à $2^{\mathrm{a}}$ Guerra Mundial; pedagogia da ação; a escola nova; a pedagogia experimental; pedagogia existencial; a escola progressiva; a educação pública; tendências atuais da educação; cooperação internacional; evolução da educação na América Latina; evolução educacional no Brasil República; visão geral da situação educacional no Brasil atual; problemas de perspectivas da educação brasileira; tendências da educação brasileira; o educador brasileiro e sua função em face ao atual momento histórico (UNIVERSIDADE FEDERAL DE UBERLÂNDIA, Planos de curso, 1977)
\end{abstract}

À primeira vista, o plano de curso pode passar a ideia de ser construído a partir de uma seleção temática e global dos conteúdos o que, na realidade, não condiz com uma análise mais atenta do material. Sendo o objetivo posto, o de construir a compreensão do processo histórico da educação nos tempos modernos, por meio do estudo da evolução dos fatos e acontecimentos, sobressai-se a perspectiva metódica da história, em que a única forma identificada de seleção foi o critério temporal clássico, marcado pela tradicional divisão da história. Outro fator inédito é a inclusão dos conteúdos referentes à educação brasileira, inexistente nos planos de outrora.

Nos anos finais de 1970 e durante toda década de 1980, a disciplina História da Educação definiu como objetivos gerais para o ensino a aquisição, por parte do estudante, de um repertório sobre o processo histórico da educação, verificando a relação entre a história geral da civilização e a história da educação e interpretando o papel exercido pela educação em diferentes momentos da história. Nesse sentido, percebe-se a introdução de uma preocupação histórica, direcionada a uma necessidade contextual de localizar no tempo e no espaço, a História da Educação. Obra recorrente nos programas de disciplina é a História da civilização ocidental, de Edward McNall Burns, publicada em 1968 pela Editora Globo de Porto Alegre.

\title{
Sem grandes pretensões ou a redefinição delas
}

Já no final dos anos 1980, a disciplina, no âmbito das proposições, passa a assumir o objetivo de "[...] possibilitar a tomada de consciência, por parte do educador, de 
que a realidade educacional brasileira foi e é constantemente produzida", visa ainda, "contribuir para o aprofundamento da compreensão da realidade educacional brasileira enquanto campo de atuação do educador em formação, a fim de que sua intervenção possa ser coerente e eficaz" (UNIVERSIDADE FEDERAL DE UBERLÂNDIA, Programas de disciplina, 1987-1995). Tal perspectiva perdurou com intensidade até meados dos anos 1990, quando nos programas, os objetivos passaram a ser bem menos pretensiosos.

O contexto da época, anos 1980, certamente colaborou e incentivou essa concepção, principalmente, por meio da introdução de uma visão crítico-ativista no ensino de História da Educação. Nessa direção, o estudo da disciplina passaria com mais frequência à análise da organização escolar brasileira, diante do foco nas questões nacionais, privilegiando o cenário sócio-econômico e político como determinantes das condições educacionais.

O conceito de transplantação cultural passa a ser o fio condutor para abordagem dos conteúdos no interior da disciplina no período. Nessa direção, assuntos como a educação jesuítica, o iluminismo, o liberalismo e o positivismo, são colocados como uma trama responsável pela perversão que ocorre na sociedade e na educação, heranças de um passado que amarra o presente deixando-o sem saída.

O enfraquecimento desse modelo ocorre a partir dos anos de 1990, quando a então perspectiva crítica da educação, que empregava, muitas vezes, o caráter "missionário" e "salvacionista" da educação passa a dar lugar a uma posição mais contextual. Assim, percebe-se que as transformações vividas nos anos 1980 e início dos anos 1990, se assentaram e encontraram lugar em um discurso mais moderado. Indicador desse processo pode ser encontrado na redefinição da bibliografia dos programas de disciplina.

\section{O imperativo dos manuais}

A primeira vista, em nenhuma outra matéria dos cursos de formação de professores, o aporte aos manuais é tão contundente quanto na História da Educação. Este formato, relacionado nas bibliografias dos programas, ano após ano, consagrou-se em modelo de leitura e de aquisição do conhecimento histórico educacional.

A bibliografia dos manuais é uma característica fundamental da disciplina, não apenas naquela que se tornou objeto da presente pesquisa, mas, na configuração do campo de forma geral. Nos anos 1960, período de criação da disciplina no curso de Pedagogia investigado, o cenário da formação de professores já previa o ensino de História da Educação nas Escolas Normais. Pode-se, portanto, considerar a existência de uma consolidada tradição do ensino da disciplina na formação do magistério nessas instituições. A configuração assumida pela História da Educação, que abriu mão de se edificar sob as bases do rigor científico para se comprometer com um ensino programático, de justificativas e receituários (WARDE; CARVALHO, 2000) fez uso irrestrito do amplo mercado editorial especializado que se abria diante do aumento da oferta desses cursos.

A Coleção Atualidades Pedagógicas, da Companhia Editora Nacional, por exemplo, foi responsável pela edição de diversos títulos de História da Educação entre primeiras edições e reimpressões. Entre outras razões, a popularização do livro entre os estudantes, bem como a prática de leitura individual pode ter incentivado a diversificação das obras e das editoras.

O fato de serem estes manuais, em grande parte, traduções de obras estrangeiras induz que esse recurso não era exclusividade dos cursos brasileiros de formação de 
professores, mas configura uma prática em diversos países do Ocidente. Quanto a isso, é necessário fazer ressalva e verificar quem foram os autores desses livros: na maioria das vezes, na Europa ou nos Estados Unidos, os próprios professores que ministravam essa disciplina.

Em síntese, as indicações de leitura na História da Educação revelaram três características básicas: (i) Uma abrangente história da educação só é possível por meio da síntese; (ii) A narrativa sequencial torna-se inevitável; (iii) A ideia evolutiva do conhecimento histórico educativo emerge mesmo das tendências mais críticas.

No desejo de alcançar a abrangência total dos conhecimentos da História da Educação, percebe-se que isso só seria possível por meio de sínteses. Daí o papel fundamental dos manuais desenvolvidos para a disciplina. Estes livros concentram "todo" arcabouço histórico educativo e, que do qual, acredita-se não poder abrir mão. Em uma das obras de Francisco Larroyo, por exemplo, dois extensos volumes se ocupam em apresentar a História da Educação desde a "sua origem". De forma sucinta, a obra está dividida em dois Tomos:

Quadro 1 - Sumário de História geral da pedagogia, de Francisco Larroyo, de 1974, obra referenciada sistematicamente nos planos de curso da disciplina

\begin{tabular}{|c|c|}
\hline \multicolumn{2}{|c|}{ Tradução de Luiz Aparecido Caruso. } \\
TOMO I & TOMO II \\
Introdução & Sexta Parte \\
Objeto, Método, Divisão e Importância da & A Época do Naturalismo \\
História da Pedagogia & Sétima Parte \\
Primeira Parte & Oitava Parte \\
A Época do Tradicionalismo & Segunda Parte \\
A Pedagogia dos Povos Clássicos & Nona Parte \\
Primeira Seção & A Educação Geral Humana na Pedagogia \\
da Revolução e do Neo-humanismo \\
A Grécia e a Pedagogia da Personalidade \\
Segunda Seção \\
Roma e a Pedagogia da "Humanitas" \\
Terceira Parte \\
A Idade Média e a Educação Cristocêntrica \\
Quarta Parte \\
A Renovação da Humanitas e a Pedagogia da \\
Reforma e da Contra-Reforma \\
Quinta Parte \\
Época do Realismo
\end{tabular}

A extensa lista de conteúdos reflete, certamente, na avolumada quantidade de páginas. Ainda assim, não se pode perder de vista a limitada exposição dada a cada tópico, algo mais exigido pela "arquitetura do impresso", expressão utilizada por Monarcha para analisar a obra, no caso, manuais de História da Educação, que leva em conta as condições e exigências não apenas teóricas e de escrita, mas gráficas e editoriais para a constituição do livro. (MONARCHA, 2009). Ressalta-se, que faz parte da obra a preocupação quanto à especificidade dos estudos de História da Pedagogia apresentando, logo no início, uma caracterização da obra por meio da definição do Objeto, Método, Divisão e Importância da disciplina. 
Tabela 1-Composição da bibliografia básica indicada nos planos

\begin{tabular}{ccccc}
\hline Anos & Manuais & Documentos & Artigos & $\begin{array}{c}\text { Obras } \\
\text { Clássicas }\end{array}$ \\
\hline 1960 & - & - & - & - \\
1970 & 12 & 00 & 00 & 06 \\
1980 & 08 & 01 & 00 & 01 \\
1990 & 06 & 05 & 05 & 01 \\
\hline
\end{tabular}

Obs.: os programas de disciplina dos anos 1960 não apresentam bibliografia.

Certamente o suporte literário mais indicado na programação da disciplina foi o manual de História da Educação. Na listagem bibliográfica, este instrumento corresponde a quatro em cada dez títulos presentes. Porém, cabe destacar, que os manuais predominantemente estão alocados na referência de leitura básica e aí, respondem por $85 \%$ das obras indicadas.

A partir do momento em que a História da Educação procura oferecer maior organicidade ao conteúdo ensinado ao longo do tempo disposto pela carga horária, favoreceu uma distribuição dos conteúdos de forma que, a História da Educação Geral ficasse a cargo do primeiro ano ou dois primeiros semestres de oferecimento da disciplina e a História da Educação Brasileira concentrada no segundo ano ou dois últimos semestres. Com isso, ficou evidente que o recurso do manual é predominante na História da Educação I enquanto que artigos e outros livros estão ligados a História da Educação II, isso demonstra que,

\begin{abstract}
A intercalação de autores brasileiros aos estrangeiros e clássicos da literatura refleteo conteúdo próprio a segunda e terceira etapa da disciplina que, em geral, tem comoreferência a educação brasileira, de forma que a opção pelos trabalhos de pesquisadorescujo objeto é esse, é a maioria (SOUZA; RIBEIRO, 2012, p. 71).
\end{abstract}

Algo em comum entre as obras mais citadas, à primeira vista, parece ser mesmo a condição de serem todos considerados manuais de História da Educação. A indicação bibliográfica nos programas, algumas vezes, acolheu vários dos títulos apresentados anteriormente de forma simultânea. Isso se deve, na exposição de Faria Filho e Rodrigues (2003), ao ecletismo que assume os programas da disciplina História da Educação, que não percebem ou ignoram tanto as diferenças de matrizes do pensamento em geral quanto as concepções historiográficas de teoria e método.

Quadro 2 - Manuais de História da Educação mais citados nos planos

\begin{tabular}{|l|l|l|}
\hline Obras & Autor & Período Citado \\
\hline História da Educação e da Pedagogia & $\begin{array}{l}\text { Narciso Lorenzo Luzuriaga y } \\
\text { Medina }\end{array}$ & $\begin{array}{l}\text { Planos de curso de } \\
1970 \text { a } 1997\end{array}$ \\
\hline História da Educação Brasileira & Maria Luisa Santos Ribeiro & $\begin{array}{l}\text { Planos de curso de } \\
1979 \text { a } 2000\end{array}$ \\
\hline História da Educação no Brasil (1930-1973) & Otaíza de Oliveira Romanelli & $\begin{array}{l}\text { Planos de curso de } \\
1982 \text { a 2000 }\end{array}$ \\
\hline História Geral da Pedagogia & Francisco Larroyo & $\begin{array}{l}\text { Planos de curso de } \\
1977 \text { a 1994 }\end{array}$ \\
\hline
\end{tabular}




\begin{tabular}{|l|l|l|}
\hline & & \\
\hline História da Educação Moderna & Frederick Eby & $\begin{array}{l}\text { Planos de curso de } \\
1970 \text { a } 1889\end{array}$ \\
\hline História da Educação na Antiguidade & Henri-Irénée Marrou & $\begin{array}{l}\text { Planos de curso de } \\
1980 \text { a 2000 }\end{array}$ \\
\hline Pequena História da Educação & Ruy de Ayres Bello & $\begin{array}{l}\text { Planos de curso de } \\
1975 \text { a } 1980\end{array}$ \\
\hline História da Educação: da Antiguidade aos nossos dias & Mario Alighiero Manacorda & $\begin{array}{l}\text { Planos de curso de } \\
1990 \text { a 2000 }\end{array}$ \\
\hline Educação e Luta de Classes & Aníbal Ponce & $\begin{array}{l}\text { Planos de curso de } \\
1983 \text { a 1997 }\end{array}$ \\
\hline História da Educação & Paul Monroe & $\begin{array}{l}\text { Planos de curso de } \\
1970 \text { a 1979 }\end{array}$ \\
\hline
\end{tabular}

Fonte: Autor (2012) com base nos programas e Sistema de Bibliotecas UFU. n/c = não consta obs.: A partir do ano 2000, a obra mais citada é CAMBI, Franco. (1999) História da Educação. São Paulo: EdUNESP.

Brevemente, ao procurar condições que indiquem a organicidade das listas bibliográficas, percebe-se que de imediato a intenção de manter atualizada a literatura da área choca-se com a prática de não revisão dos títulos em voga, ou seja, o fato de incluírem novas obras, novas perspectivas parece não entrar em conflito com modelos explicativos anteriores e, assim, há uma acumulação de indicações, intencionando que caberá ao docente fazer uma segunda seleção da bibliografia de acordo com seu perfil.

$\mathrm{Na}$ intenção de identificar linhas gerais capazes de compreender o perfil bibliográfico dos planos, observa-se a existência de ao menos quatro perspectivas presentes na composição da literatura referenciada para disciplina: (i) História da Educação como história da cultura; (ii) História da Educação, progresso e democracia; (iii) História da Educação entre determinismos político e econômico -influências do marxismo; e, (iv) História da Educação erudita.

A primeira linha bibliográfica expressa a História da Educação como história da cultura. Nessa perspectiva, encontram-se as obras de Lorenzo Luzuriaga, que segundo Gatti Jr. (2011), são marcadas pela intenção de realizar uma história da pedagogia baseada nos preceitos do vitalismo, ou a centralidade no tema da vida, localizando a pedagogia, a partir de Dilhtey, como integrante das ciências do espírito. Assemelha-se a essa posição a obra de Francisco Larroyo, o qual

[...] toma o objeto da história da pedagogia como referido, de um lado, ao que de mais profundo e significativo ocorreu desde o passado mais remoto (profundidade). Por outro lado, refere-se ao fato pedagógico, à teoria educativa e à política educacional (extensão), tomando o fato pedagógico como modo de realização, no espaço e no tempo, do acontecimento de assimilação da cultura e dos fatores que determinam, sendo que, primeiramente, cabe à história da pedagogia compreender e narrar [...] (GATTI JR, 2011, p. 61)

Segundo um dos editores da obra de Dilthey, Otto Friedrich Bollnow, o interesse dele pela Pedagogia estaria na sua profunda atitude filosófica. Segundo o editor, no prólogo de Fundamentos de um sistema de pedagogia, publicado pela Editora Losada de Buenos Aires, Dilthey, sistematicamente, afirmava que toda filosofia desemboca em uma 
pedagogia. Nas palavras extraídas do texto de Dilthey, "A última palavra de um filósofo... é a pedagogia [...] Ou ainda, "o fim de toda verdadeira filosofia é a pedagogia no seu mais amplo sentido, como teoria da formação do homem" (BOLLNOW, 1940). Nesse sentido, a fundamentação da história como investigação da cultura, da filosofia vitalista, e da pedagogia como parte integrante das ciências do espírito, se fez presente em duas importantes obras referenciadas nos programas de História da Educação da UFU.

A segunda linha assume a perspectiva História da Educação, progresso e democracia.Segundo Silva e Gondra (2011), essas características permearam a constituição dos textbooks, manuais norte americanos de História da Educação, sobretudo, os escritos por Paul Monroe e, que aqui, se estende a Frederick Eby. Nesse movimento,aparecerem as obras de Paul Monroe e Frederick Eby entre as principais contribuições. Esses autores são marcados pelo espírito de progresso civilizatório de marco democrático, pela difusão da filosofia de vida norte-americana por meio da educação.

Quanto a Paul Monroe, "nesse ponto, mais do que a síntese de grandespersonagens e ideais pedagógicos, em sua narrativa histórica, a educaçãose apresenta como uma intervenção social [...]"'(SILVA; GONDRA, 2011, p. 710).

Frederick Eby, além de imprimir tais características, apresenta forte influência religiosa cristã, tendo sido conhecido como um dos grandes historiadores do cristianismo nos Estados Unidos. Era integrante da religião Batista, a qual havia se convertido e demonstra grande entusiasmo (TEXAS STATE HISTORICAL ASSOCIATION, 2012), apesar de alguns de seus textos refletirem uma flexibilidade quanto a esta filiação, por exemplo, quando aborda o naturalismo pedagógico de Rousseau, algo que, certamente, merece investimento futuro.

Nota-se ainda, que ambos tiveram influência do pensamento de Dewey. Monroe atuou junto a ele no Teachers College, exercendo influência nas propostas curriculares norte-americanas. Eby, aluno de Dewey, posteriormente se opôs as ideias seculares e pragmáticas de seu mestre, permanecendo fiel a sua designação cristã e o objetivo da formação espiritual por meio da educação (TEXAS STATE HISTORICAL ASSOCIATION, 2012).

Como terceira linha bibliográfica, aparece a História da Educação entre predominância do político, econômico e a influênciado marxismo.Percebe-se, no transcurso dos anos 1970 aos 1990, o movimento de inclusão de um novo perfil de obras brasileiras com atenção ao contexto educacional regional, movimento que ganha expressão a partir da organização dos Programas de Pós-Graduação em Educação. Antes disso, a presença de obras nacionais é conhecida, no entanto, esses livros têm como características a configuração da área de História da Educação por "professores-operadores de artefatos impressos, pelos quais, inadvertidamente, se instituiu uma tradição prático-discursiva [...]" sendo, posteriormente substituída "por uma profissionalização da historiografia universitária” (MONARCHA, 2009, p. 70).

A primazia política e o determinismo econômico aparecem nos textos de Maria Luisa Santos Ribeiro e Otaíza Oliveira Romanelli, obras frequentemente relacionadas nos programas do período analisado. Com obras marcadamente influenciadas pelo marxismo, dentre esse perfil de indicações de leitura destaca-se Educação e Luta de Classesde Aníbal Ponce, que esteve relacionada na listagem bibliográfica nos anos 1980 e 1990 além de uma diversidade de outros textos que não são declarados manuais.

Por fim, a quarta linha bibliográfica é definida como uma História da Educação erudita. Nessa condição, três obras estiveram relacionadas na bibliografia dos programas pesquisados, História da Educação na Antiguidade de Henri Irineu Marrou, História da 
Educação: da Antiguidade aos nossos dias de Mario Alighiero Manacorda e História da pedagogia de Franco Cambi.

Estas obras são marcadas pela diversificação das fontes utilizadas na construção dos textos, demarcando um espaço de cultivo da tradição educativa por meio das composições da cultura humana sendo que o Marrou trás linhas de um Humanismo Clássico, Manacorda, apóia-se em um Marxismo erudito e Cambi, por sua vez, em um ecletismo que predomina o pensamento foucaultiano. Conforme Marrou, "[...] a educação não é um destes elementos que se podem comunicar, em estado puro, de uma civilização a outra: sumo e estrato de uma cultura, ela é inseparável de sua Forma, e com ela parece" (MARROU, 1975, p. 14). O recurso aos textos antigos é uma prática fundamental para essas obras e se fazem presente no decorrer dos textos.

$\mathrm{Na}$ consideração realizada por Carlos Monarcha (2009) sobre os manuais de História da Educação, esse tipo de material de leitura representou por muito tempo, mais do que uma tipologia de imprensa, uma organização ideológica de defesa do passado, da sua petrificação e repouso, para que diante das questões emergentes do presente, possa-se dali, tirar lições proveitosas para alertar o educador das armadilhas da história. Assim,

\begin{abstract}
Ainda que limitadas a informar a vulgata histórica, as sínteses escolares de História da Educação, nas suas várias fisionomias, são, indubitavelmente, objetos impressos que colocaram em jogo a apreciação do passado antigo e do presente imediato. Em nome da clareza, método, objetividade e acessibilidade, os autores empreenderam um reconto seco do essencial do passado humano; nesse recontar, idealização e silêncio se contemplavam (MONARCHA, 2009, p. 90)
\end{abstract}

No entanto, o autor também incide seus questionamentos ao tempo contemporâneo, uma vez que, a figura do manual de História da Educação permanece ainda presente, em busca de compreender que caminhos tomam esses objetos. Segundo ele, as produções atuais tendem a:

(i) enunciar o "combate pela História" e o "fazer história", quer promover junto aos utilizadores os discursos históricos consubstanciais aos métodos cognoscitivos avançados; (ii) reage à "história tradicional", tão-somente inventário de memória contido em quadros extremamente apertados, nos quais tudo se vê sem nada se ver; (iii) deseja liberar o recalco, promover desvios, preencher lacunas e fazer falar o silêncio; (iv) fende o monolitismo cultural e religioso, ao desfazer esteriótipos de classes, gêneros, étnicos e nacionais; (v) recusa o relato linear e as modalizações totalizantes, volta-se para a diversidade, descontinuidade e permanências, logo, interdita a escrita de uma história unificada, vazia e linear; (vi) por dispor temas problemas, questiona, não se limita ao fazer aprender, quer fazer refletir e pensar (MONARCHA, 2009, pp. 90-1).

Assim, Monarcha (2009) encerra argumentando que a prática de produção de manuais de História da Educação não acabou com o risco que incorre em pretender a síntese ideal da educação. No entanto, tendo sua concepção de História revisada, o alargamento do que são os processos educativos e a humildade de compreender que se trata de uma obra extensa, mas breve nas possibilidades interpretativas, o manual passa a ser fonte importante para o desenvolvimento do senso crítico. 


\section{O trânsito bibliográfico}

Basicamente, os manuais, nos estudos de História da Educação Geral são peças fundamentais no desenvolvimento da disciplina. Abordar o estudo de tempos e lugares distantes em muitos dos casos, só é viabilizado por meio deste suporte. No entanto, a sedução do manual também tem alcançado o tratamento de temas da História da Educação no Brasil, por isso, acredita-se haver um predomínio, senão um imperativo, do uso deste tipo de material na disciplina. A seguir uma amostra do trânsito marcado por entradas e saídas de obras referenciadas nos planos, indícios de transformação na disciplina do ponto de vista ideal.

Quadro 3 - Principais* entradas na listagem bibliografia

\begin{tabular}{|c|c|}
\hline Anos & Títulos \\
\hline 1970 & $\begin{array}{l}\text { PAIVA, V. P. Educação popular e educação de adultos } \\
\text { NAGLE, J. Educação e Sociedade no Brasil 1920-1929 }\end{array}$ \\
\hline 1980 & $\begin{array}{l}\text { AZEVEDO, F. de. A transmissão da cultura } \\
\text { CUNHA, L. A. Universidade Temporã } \\
\text { RIBEIRO, M. L. S. História da Educação no Brasil } \\
\text { RIBEIRO, M. L. S. Introdução à História da Educação brasileira } \\
\text { ROMANELLI, O. O. História da Educação no Brasil (1930-1973) }\end{array}$ \\
\hline $\begin{array}{l}1990 \\
2000\end{array}$ & $\begin{array}{l}\text { MANACORDA, M. A. História da Educação. Da antiguidade aos nossos dias } \\
\text { XAVIER, M. E. S. P. Poder Político e Educação de Elite } \\
\text { CAMBI, F. História da Pedagogia }\end{array}$ \\
\hline
\end{tabular}

(*) o termo "principais" deve-se ao fato de em determinado período uma obra passar a ser referenciada constantemente ou no caso contrário, após ser relacionada por muito tempo deixou de ser anunciada na bibliografia.

Fonte: Autor (2013) com base nos programas/planos de curso (FFCLU/UnU/UFU).

A movimentação bibliográfica indicada no quadro anterior inspira a percepção de mudança teórico-metodológica no interior da disciplina, sem perder de vista, no entanto, o manual enquanto formato. As principais entradas concentram-se nos anos 1980, período que acolhe diversas transformações sociais, acadêmicas e teóricas para o campo da História da Educação. O ingresso de uma perspectiva crítica da escola está marcadamente presente, fazendo assumir a disciplina uma combinação das perspectivas marxista concentradas em Althusser e, sobretudo, Gramsci e uma pedagogia da existência de Paulo Freire. As baixas, por seu turno, são marcadas pela saída de obras clássicas do estudo da História da Educação, bem como, o abandono da concepção revolucionária da escola.

Quadro 4 - Principais*baixas na listagem bibliografia

\begin{tabular}{|ll|}
\hline Anos & Títulos \\
\hline 1970 & $\begin{array}{l}\text { RIBOULET, L. História da Pedagogia } \\
\text { HUBERT, R. História da Pedagogia }\end{array}$ \\
\hline 1980 & $\begin{array}{l}\text { ATINKSON, C. y MALESKA. História de la Educación } \\
\text { BELLO, R. A. Pequena História da Educação } \\
\text { CRAMER Y BROWNE, Educação contemporânea } \\
\text { EBY, F. História da Educação Moderna }\end{array}$ \\
\hline 1990 & $\begin{array}{l}\text { LARROYO, F. História Geral da Pedagogia } \\
\text { LUZURIAGA, L. História da Educação e da Pedagogia } \\
\text { MONROE, P. História da Educação }\end{array}$ \\
\hline 2000 & $\begin{array}{l}\text { MARROU, H. I. História da educação na Antiguidade } \\
\text { PONCE, Aníbal. Educação e luta de classes }\end{array}$ \\
\hline
\end{tabular}

(*) Segue mesmoentendimento do Quadro 1.

Fonte: Autor (2012) com base nos programas/planos de curso (FFCLU/UnU/UFU). 
O desaparecimento, a substituição e o ingresso de obras nos programas não podem assegurar que tais ações repercutiram mudanças profundas na História da Educação ensinada, pois, deve-se prever que na hipótese de uma substituição abrupta, o docente poderia percorrer o caminho da omissão do uso em defesa de um ou outro aporte teóricometodológico. Ou ainda, a dificuldade de apropriação de uma determinada obra justificaria a leitura/permanência de outras.

No entanto, é observado que a partir desse momento de transição, a História da Educação passou a objetivar uma "[...] compreensão da realidade educacional brasileira em seu contexto sócio-histórico, com o intuito de permitir ao aluno fazer uma reflexão sobre as condições históricas que possibilitaram a emergência dessa mesma realidade [...]" (UNIVERSIDADE FEDERAL DE UBERLÂNDIA, Programas de disciplina, 1997-1998), delineando assim, projeções menos idealistas ou utópicas para o ensino da disciplina, que abandonou o caráter intervencionista para assumir uma concepção de compreensão e análise da realidade educacional.

\section{Em busca de uma História da Educação total}

Ao longo dos quarenta anos analisados, a amplitude dos conteúdos apresenta-se como característica recorrente nos programas de disciplina. Essa parece ser ainda, uma característica comum, tanto em âmbito nacional quanto internacional. Para Nunes (2003), um dos problemas básicos que a História da Educação enfrenta é o tratamento do conteúdo tido em muitas vezes como denso e enciclopédico, o que, de certa forma, colabora ao questionamento do sentido de aprender a matéria em questão, devido à falta de contextualização e aprofundamento do debate.

Segundo Maria Teresa Santos (2007), ao abordar a sistematização dos conteúdos "nos programas de História da Educação em Portugal verificam-se duas tendências extremadas: ou são extensos ou compreensivos" (p. 244). Nessa direção, a dualidade se expressa tanto na preocupação em subsidiar a formação do estudante por meio do mais amplo repertório possível, quanto na pretensão de esgotamento de todas as histórias educativas em um tempo limitado.

Na disciplina História da Educação, por exemplo, aos seus estudantes é proposto,a partir de uma leitura geral dos programas, que aprendam toda história ocidental da educação, da Antiguidade à Idade Média, do Moderno ao Contemporâneo, em dimensão local e global, o que, grosso modo, tem imprimido uma característica funcional de repositório. Esta compreensão acerca do caráter armazenador que a disciplina tem assumido se estabelece dado que mais cedo ou mais tarde, novos assuntos e temáticas são acrescentados ao conteúdo a ser abordado, uma vez que estes já pertencem à ordem do passado.

A condição cumulativa dos conteúdos da disciplina pode, assim, ser visualizada na trajetória histórica dos planos de curso nos três grandes períodos identificados. Dessa forma, se no primeiro momento, de 1961 a meados dos anos 1970, os conteúdos estão, basicamente, concentrados em uma perspectiva clássica de História da Educação com presença marcante da Filosofia e Filosofia da Educação, a partir da metade dos anos setenta, a disciplina volta-se à História, ainda que em perspectiva tradicional no que diz respeito à teoria e método, centrada no estudo histórico da educação. Ocorre ainda, nesse período, a inclusão da educação brasileira como conteúdo. Nessa direção, a partir do final 
dos anos 1980 e, sobretudo, a partir de 1990, a marca repositória que carrega a disciplina fez com que acolhesse novos temas ao já extenso conjunto de matérias.

Mais uma vez, a extensão dos conteúdos apresenta-se como um problema fundamental da organização disciplinar da História da Educação, que caba por deixar transparecer problemas mais profundos de ordem teórica, metodológica e didática, que imprecisas, precedem o questionamento presente da necessidade e importância desta disciplinaem permanecer nos currículos.

Assim, a atividade de seleção de matérias pode ser compreendida como reflexo ou consequência de um conjunto de elementos bem mais complexos que constituem o saber a ser ensinado. Na História da Educação, alguns desses elementos se revelam no limiar da constituição da própria disciplina, como a "despreocupação com o estatuto epistemológico"; "quase ausência de referência à disciplina como matéria historiável". (SANTOS, 2007, p. 243); a falta de "uma cultura histórica sólida" aos iniciados no estudo da disciplina; e a necessidade de equilíbrio entre "tradição e inovação" (FARIA FILHO \& RODRIGUES, 2003).

\section{A pouca ênfase quanto ao estatuto epistemológico}

Na disciplina História da Educação ofertada na UFU podem-se encontrar indícios dessa afirmativa, ao longo do tempo, nos diversos contextos vivenciados pela disciplina, que extrapolam mesmo o âmbito do ensino de História da Educação local, da regionalização da educação superior e das condições sociais e econômicas de cidade responsável por impor, inicialmente à instituição, uma identidade de universidade de ensino. Além disso, no contexto mais amplo, esse tipo de preocupação veio à cena há pouco mais de vinte anos, no âmbito da pesquisa sobre o ensino de História da Educação, possíveis a partir da consolidação de programas de pós-graduação, linhas de pesquisa e grupos envolvidos com a temática.

Isso, de fato, pode ter contribuído para que ocorresse um agrupamento eclético em um mesmo plano de curso, de autores e obras sem um propósito relacional - crítica ou debate e, na presença reduzida de títulos que problematizassem a própria disciplina ou o conhecimento do qual trata revelam a deficiência do trato da questão epistemológica para a disciplina, também algo possível apenas no contexto profícuo para o debate acerca do ensino de História da Educação nos últimos vinte anos.

Dessa forma, certamente, a transição das matrizes epistemológicas que fundamentaram a História da Educação passaria por despercebido, caso não fosse uma presença secundária dos seus porta-vozes, autores dos manuais que ingressavam ou abandonavam o elenco bibliográfico dos programas, uma vez que, a indicação da abordagem dos conteúdos nos programas manteve-se a mesma.

Outro elemento que pode elucidar o estágio de estabilidade da História da Educação ensinada é a sua presença no próprio currículo do curso de Pedagogia, limitada, de modo geral, à exigência legal de oferecimento da disciplina de início e, posteriormente, à consolidação ou acomodação dos modelos curriculares.

Esse problema, no entanto, é comum à História da Educação em geral, quando nos "programas também se pode constatar a inexistência de linhas de enquadramento informativo quanto ao lugar relativo da disciplina no quadro das Ciências da Educação [...] ou ainda, sobre o seu valor formativo específico" (SANTOS, p. 244) no currículo em que se inscreve. 


\title{
Ausência de referência à disciplina como matéria historiável
}

Quanto a isso, é necessário ponderar que a História da Educação sempre esteve intimamente ligada à Educação, à Pedagogia e ao acolhimento que este campo propiciou. Nesse sentido, se há registros escassos quanto à abordagem de fontes primárias na disciplina e críticas teórico-metodológicas, mais do que fragilidade, isso indica a complexidade que assume o ensino de História da Educação da sua origem aos dias atuais. Contudo, em busca desses indícios historiáveis, registram-se referências às Constituições, Federal e do Estado de Minas Gerais, 1977, Anais das Conferências Brasileiras da Educação, a obra Didática Magna e o Manifesto dos Pioneiros da Escola Nova.

Além disso, é necessário ressaltar o surgimento, ainda que restrito, de programas que criaram uma justificativa para a disciplina, ou seja, um elemento adicional que se encarregou de oferecer informações acerca da sua localização e especificidade. Isso ocorre a partir de 1990, quando é possível encontrar, a exemplo do plano de curso de 1991, referências como: "A história da disciplina "História da Educação" no Brasil, não se dissocia da história do Curso Normal [...]". A presença de justificativa da disciplina nos seus planos possibilitou encontrar objetivamente, a posição teórica e ideológica de cada programa, bem como, referências à própria História quando, por exemplo, define que a

\begin{abstract}
[...] proposta de trabalho para o Curso de História da Educação - anual de 1991 parte do pressuposto de que a História não é o mero desenrolar de fatos ou ideias (concepção positivista), mas uma ciência que busca apreender o momento da vivência do homem em contato com outros homens produz constantemente sua própria existência (concepção do materialismo histórico) (UNIVERSIDADE FEDERAL DE UBERLÂNDIA, Programa de Disciplina, 1991).
\end{abstract}

Percebe-se, que desde então, a preocupação teórica, histórica e espacial, de localização e compreensão da disciplinar no interior das ciências da educação, bem como, no projeto de formação do qual faz parte, contribuiu para o surgimento de abordagens, no âmbito dos conteúdos, como a História da História da Educação e a História da Educação no Triângulo Mineiro e Alto Paranaíba, sendo que a primeira reflete tanto a preocupação sobre o ensino como a inserção do grupo de docentes da instituição no contexto da pesquisa sobre a temática e, a segunda, demonstra o reflexo da Pós-Graduação e dos resultados de pesquisas no ensino, o que marca não apenas o ingresso dos estudos da educação local nos planos de curso, mas, a mudança no perfil bibliográfico da disciplina, que para este conteúdo passa a prever produções dos próprios professores.

\section{A falta de uma cultura histórica}

A falta de uma cultura histórica sólida, por sua vez,acaba por revelar o problema emblemático da própria História e do conhecimento histórico na sociedade moderna. De um lado, tem-se aversão ao passado por meio da primazia do presentismo como chama atenção Durkheim, do "presente contínuo" como argumenta Hobsbawm ou "do tempo do não mais e do ainda não", conforme Arendt.Por outro, a dificuldade que o conhecimento histórico escolar, fixado na transmissão da História como algo descolado da realidade às crianças, adolescentes e adultos em fase de escolarização, enfrenta em cultivar esse saber como substancial à vida como um todo.

As dificuldades do estudante de História da Educação, que ao estudar a estruturação dos sistemas nacionais de educação na Europa, não consegue contextualizar 
ao período histórico da edificação dos estados nacionais, da influência da Revolução Francesa para um ensino público e estatal, do desenvolvimento científico e capitalista, ou mesmo situar aonde é a Europa é exemplo de ausência ou pouco alcance do conhecimento histórico sobre a formação das gerações em período escolar. De algum modo, o estudante que apresenta resistência ao estudo do passado, pode ser fruto de um ou dos dois elementos dessa crise.

\section{Tradição e inovação}

O Equilíbrio entre tradição e inovação ou a necessidade de tal estado, aparece na relação conflituosa entre o passado e o futuro, que, consequentemente, ocorre no tempo incerto do presente, do qual anuncia, na forma de uma profunda crise da cultura, Hannah Arendt. Nessa direção, constantemente, encontram-se em conflito, um mundo velho e seus recém-chegados, crianças, basicamente, mas também imigrantes. Vive-se, dessa forma, em meio à necessária transmissão de uma tradição ao tempo que é esperada uma necessária inovação da mesma.

O sentido de inovação parece não ser mais aquele apreendido enquanto processo de modernização, isso, porque, os parâmetros modernos parecem não mais constituírem as diretrizes que governam os desejos de mudança. Esse estado de desejo, hodiernamente, é por si só, potencial, explicativo e auto-suficiente. O desejo de mudança se encerra nele mesmo, no desejo. Por desprezar o passado e encarar o moderno como já ultrapassado, o desequilíbrio entre tradição e inovação se escancara em um passado conservador, um futuro sem perspectiva e um presente atemporal.

A possibilidade de encontrar equilíbrio pode residir na iminente valorização da história como conhecimento do passado, isso porque, "após o predomínio autoritário [...] da história como construção do futuro, que durou aproximadamente de 1789 a 1989" (REIS, 2006, p. 226), surge, segundo Reis, não como ação conservadora ou contrarevolucionária, mas, como projeto histórico, um movimento que visa reconstruir o passado ora negligenciado.

Logo, esses elementos podem ser encontrados implícita ou ocultamente nas práticas internas do curso, na relação dos saberes que constituem o currículo, nas disputas por espaço, na personalidade de quem assumiu o ensino do conteúdo, e, no que interessa na ocasião, podem ser encontrados nos programas da disciplina analisada, sobretudo, pelo perfil bibliográfico adotado, mostrando as movimentações na literatura selecionada, os conflitos combatidos e os convividos pela História da Educação na construção da sua história disciplinar na UFU.

\section{Considerações finais}

A composição dos repertórios da disciplina História da Educação demonstra, em linhas gerais, ter havido um movimento menos intenso de transformação na dimensão ideal da disciplina, basicamente, marcada por movimentos mais lentos e mais visíveis da operacionalização do ensino, como por exemplo, as mudanças de conteúdo, os objetivos e a bibliografia. Mais intensas são, ao que tudo indica as mudanças na dimensão real, palco das realizações, adequações e transgressões ao programado.

Acredita-se, que a partir da leitura e compreensão dos programas, esses elementos: objetivos, conteúdos e bibliografias apresentam a função ideal desempenhada pela disciplina, resumidas a três aspectos complementares, construídos a partir de 
definições dos próprios conceitos de legitimidade, autonomia e especialização da História da Educação, desenvolvidos por Nóvoa (1996); Magalhães (2003); Mogarro (2006); Santos (2006) e que tiveram repercussão em estudos e pesquisas em Portugal e no Brasil..

O primeiro aspecto é a busca por parte da História da Educação do estabelecimento da sua função de saber legítimo, na formação de profissionais e pesquisadores da educação. Somam-se a este conjunto de saberes legítimos, as disciplinas que fundamentam a educação (História, Psicologia, Sociologia, Didática, Biologia) ou que dela desdobram-se análises especializadas (Metodologias).Esse ideal é perceptível aolongo da trajetória curricular da disciplina, sustentado, grosso modo, por um cenário de continuidade de oferecimento, de lenta expansão para algumas outras licenciaturas e seu espaço na Pós-Graduação.

Osegundo se consolida por meio da existência de rupturas, principalmente, no entendimento acerca do que consiste a discussão dos conteúdos históricos educativos na formação de profissionais da educação, que pode ser demonstrada no deslocamento de uma percepção curricular religiosa católica para um currículo técnico e depois, para uma concepção propriamente histórica, o que demonstra a redefinição dos princípios da disciplina, que agrega maior valor acadêmico, defendendo assim, a função de saber autônomo, devido ainda, à atualização teórica dos próprios professores por meio dos programas de formação em serviço, o que tornou possível a divulgaçãode novas diretrizes para o ensino de História da Educação.

O currículo técnico está presente no curso de Pedagogia desde as primeiras formulações do curso nos anos 1930 e, posteriormente, nas determinações do CFE estendese até os anos 1990. O que apresenta mudanças, no caso do objeto pesquisado, é a presença religiosa nos currículos, que é predominante por conta da influência religiosa no interior do curso.

Por sua vez, o grau de desenvolvimento interno da disciplina História da Educação, alavancado pelas transformações operadas nos anos 1990, é representado pelodesejo dese estabelecer como saber especializado, pois, acredita-se já encontrar espaço consolidado no currículo e nos demais espaços de disputa disciplinar, com presença no ensino (mesmo que minimamente) e também na pesquisa, a exemplo da manutenção de uma linha de História e Historiografia da Educação no âmbito do Programa de PósGraduação em Educação da instituição pesquisada. Dentre as transformações citadas estão contratações de novos professores; mudanças na legislação de ensino que geraram impactos na formação de professores; o desenvolvimento do Programa de Pós-Graduação em Educação; a criação do NEPHE e; especialmente, a introdução de conteúdos sobre a história da educação local a partir da produção acadêmica dos próprios professores.

\section{Referências}

BOLLNOW, O. F. Prólogo da edição argentina. In: W. F. DILTHEY, Fundamentos de un sistema de pedagogia. Buenos Aires: Losada, 1940, p. 7-10.

BONTEMPI JR, B. O ensino e a pesquisa em História da Educação Brasileira na Cadeira de Filosofia e História da Educação (1933-1962). História da Educação , 2007, 79-105. 
FARIA FILHO, L. M., \& RODRIGUES, J. R. A história da educação programada. uma aproximação da história da educação ensinada nos cursos de pedagogia da Belo Horizonte. Revista Brasileira de História da Educação , 2003, 159-175.

GATTI JR, D. Intelectuais e circulação internacional de ideias na construção da disciplina História da Educação no Brasil (1955-2008). In: M. M. CARVALHO, \& D. GATTI JÚNIOR, O ensino de História da Educação (pp. 47-93). Vitória, ES: EDUFS, 2011.

MAGALHÃES, J. Fazer e ensinar História da Educação. Braga, Portugal: Universidade do Minho, 2003.

MARROU, H. I. História da Educação na Antiguidade. São Paulo: EPU, 1975.

MONARCHA, C. Práticas de Escrita da História da Educação: o tema da Escola Nova nos manuais de autores brasileiros. In: D. GATTI JÚNIOR, C. MONARCHA, \& M. H. BASTOS, $O$ ensino de História da Educação em perspectiva internacional. Uberlândia: Edufu, 2009, p. 65-94.

NÓVOA, A. História da Educação: novos sentidos, velhos problemas. In: J. (. MAGALHÃES, Fazer e ensinar História da Educação. Braga, Portugal: Universidade do Minho, 1996, p. 35-54.

NUNES, C. Ensino e historiografia da educação. problematização de uma hipótese. Revista Brasileira de Educação , 1996, p. 67-79.

NUNES, C. O ensino da História da Educação e a produção de sentidos na sala de aula. Revista Brasileira de História da Educação. v. 6, 2003, 115-157.

REIS, J. C. História e Teoria. historicismo, modernidade, temporalidade e verdade. Rio de Janeiro: FGV Editora, 2006.

SANTOS, M. T. Perfil da História da Educação: conflitos entre o empobrecimento efectivo e o potencial objectivo. In: J. PINTASSILGO, L. ALVES, L. CORREIA, \& $\mathrm{M}$. FELGUEIRAS, A História da Educação em Portugal: balanços e perspectivas. Porto: Asa, 2007, p. 229-256.

SILVA, J. C., \& Gondra, J. G. Textbooks in the History of Education: notas para se pensar as narrativas de Paul Monroe, Stephen Duggan e Afrânio Peixoto. Revista Brasileira de Estudos Pedagógicos , 2011, p. 702-722.

SOUZA, S. T.; RIBEIRO, B. O. L. Ensino de História da Educação no Brasil: reflexões sobre o perfil de professores e suas metodologias. História da Educação - RHE. v.16 n.36 jan./abr. 2012, p. 60-76.

TEXAS STATE HISTORICAL ASSOCIATION. Eby, Frederick - 1968. [biografia] Disponível em < http://www.tshaonline.org/handbook/online/articles/feb03> Acesso em 13/11/2012. 
WARDE, M. J. Questões teóricas e de método: a história da educação nos marcos de uma história das disciplinas. In: D. SAVIANI, J. C. LOMBARDI, \& J. L. SANFELICE, História e História da Educação: o debate teórico metodológico atual. Campinas: Autores Associados, 1998, p. 88-99.

; CARVALHO, M. M. Política e cultura na produção na produção da História da Educação no Brasil. Contemporaneidade e Educação, 2000, p. 9-33.

UNIVERSIDADE FEDERAL DE UBERLÂNDIA, Planos de curso da disciplina História da Educação, 1961-1969; 1970-1977; 1978-2000

Revista comemorativa do jubileu de prata da FFCLU. Uberlândia, 1985.

\footnotetext{
${ }^{1}$ Mestre em Educação: História e Historiografia da Educação pela Universidade Federal de Uberlândia. Professor de Filosofia da Educação e Fundamentos Filosóficos Sócio-Históricos da Educação na Universidade Federal de Goiás, Campus Catalão. E-mail: bruno_borges@ufg.br

${ }^{2}$ Doutor em Educação: História e Filosofia da Educação pela Pontifícia Universidade Católica, com estágio de pós-doutorado concluído na Faculdade de Educação da Universidade de São Paulo. Professor de História da Educação na Universidade Federal de Uberlândia. Bolsista de Produtividade em Pesquisa do CNPq Nível 1C. Beneficiário do Programa Pesquisador Mineiro da Fapemig. E-mail: degatti@ ufu.br
}

Recebido: abr-13 Aprovado: set-14 